\title{
AUTOBIOGRAFIA IN PROGRESS COM HH: ESTADO DE SÍTIO [MEDO E VIOLÊNCIA]
}

Frederico Canuto ${ }^{1}$

RESUMO: O presente artigo busca revelar as operações desempenhadas por Herberto Helder em sua obra Photomaton e Vox de modo a sustentar a hipótese da criação de um corpo escrito fluido, comunal e silencioso a partir de um processo de leitura-escritura.

PALAVRAS-CHAVE: Corpo, Escrita, Comum

ABSTRACT: This article seeks to expose the operations performed by Herbert Helder in his book Photomaton \& Vox to support the idea of creation of a fluid, common and silent body through a dialectical reading and writing process.

KEY WORDS: Body, Writing, Common

\section{[para ler em voz alta]}

\section{Ler-escrever-com}

Uma afirmação escrita por Herberto Helder em Photomaton e Vox dá a dimensão exata de sua escrita memorialística: "a experiência é uma invenção” (HELDER, 2006, p. 66). Tomando o tema memória como parte de um processo de fabulação do próprio autor através da escrita, a partir desta afirmativa quatro linhas atravessam sua literatura do ponto de vista da produção de memória.

Um: só é possível escrever sobre o processo de memória-esquecimento helderliano discutido pelo próprio em Photomaton e Vox se sua autobiografia for pensada como invenção de uma experiência própria pela sua representação escrita. Isso implica dizer que qualquer representação da experiência anterior é por si só um outro invento, o que acaba por garantir a inacessibilidade de algo que possa ser primeiro. Semelhante é o procedimento feito em Ouolof. Poemas mudados para o português pelo autor português, onde o original é por si só um invento em forma de poema de outro

\footnotetext{
${ }^{1}$ Doutorando na Faculdade de Letras da Universidade Federal de Minas Gerais, na área de concentração Literatura Comparada e linha de pesquisa Poéticas da Modernidade.
} 
autor que dará lugar a um novo durante o processo de transformação-tradução: a mudança para o português. Tradução e produção poêmica nestas duas obras convergem e se equivalem como processo de escrita tendo em vista que em ambos casos aponta-se para o desaparecimento de uma referência primeira à qual o poema produzido $a$ posteriori, por exemplo, possa ser comparado. Assim, não procede nesta escrita da memória a referenciação a algo anterior, que possa ser chamado de real e/ou factual, que se coloque como primeiro e a escrita do autor português como produto deste.

Dois: sendo a memória então produto de uma fabulação, seus textos poéticos nada mais são que invenções sucessivas a partir de estratégias de escrita bem delineadas - só assim pode-se construir um corpo imagético do que é a sua literatura desenhada ao longo de suas obras poéticas. Assim, não é tanto o que se escreve - pois não há referência que comprove conceitos como realidade ou ficção, separando-os, ou elementos que se repetem num mesmo contexto -, mas como se escreve a questão nevrálgica que pode iluminar os modos de escrita presentes em Helder.

Três: este movimento de produção em série coloca “[...] em prática um conceito de poesia em que o produtor [autor] é um leitor: agora [como em Llansol] escrever é ler [outros, outrando-se em português] [...] introduzindo na escrita uma dimensão interactiva e performativa [...]" (BARRENTO, 2006, p. 182). Helder em suas traduções e produções literárias constantemente reinventa o que coloca como memória, esquecendo e reproduzindo a partir de um processo onde leitura e escritura se complementam fazendo parte de um processo memória-esquecimento.

Neste desenvolvimento com a escrita possuidora de uma dimensão interactiva, depreende-se que o leitor tem papel fundamental pois ele também, a partir da obra Helderliana, aderindo a mesma, lê-escreve. Porém, o faz com o autor performatizado pela escrita, pois é uma interação. Escrever em companhia do autor diz de um posicionamento ao seu lado, onde este não é início e nem referência-mestra. Ao se colocar numa situação de estar junto, tanto escritor quanto leitor, suplementam-se simbioticamente: um com o outro.

Quatro: se a vida produzida ou experiência inventada através da poesia continua mesmo após a escrita pelo movimento ler-escrever, traduzindo-se e deslocando-se em outros textos, a autobiografia feita através da leitura-escritura é in progress tanto para o leitor como para o autor-produtor. Constantemente, o ponto final da autobiografia de 
Helder se transforma em reticências na medida em que ler-escrever é movimento infindável em constante produção tanto pelo autor como pelo leitor. Assim, a memória não é referência imutável, mas movimento produtivo. As imagens tanto poéticas como as que se apresentam ao longo de seu texto em prosa em Photomaton e Vox nunca são as mesmas, apesar de serem usadas as mesmas palavras.

\section{Lendo para escrever com}

$\mathrm{Na}$ autobiografia de Helder, ler-escrever são operações desempenhadas a fim de produzir uma escrita singular em constante processo de fabulação memorialística. Pensando que tal movimento se dá em uma interação do leitor com o autor performatizado pela escrita, um corpo em comum é produzido. Como ele é escrito nesse em-comum é questão balizada em dois pontos.

Primeira baliza: sobre o esquecimento. Não é sobre o esquecimento como categoria filosófica que se está a escrever. Nem analisar o que está a se esquecer na obra de Helder, especificamente numa obra em prosa ou poema específico - o que é tarefa do leitor: dar sentido ao texto, lendo-escrevendo, sem referências que possam ser chamadas verdadeiras, próprio do texto Helderliano. Esquecimento e memória tal como ele os concebe e desenvolve é aderir à própria constituição de uma obra literária, pois é feita

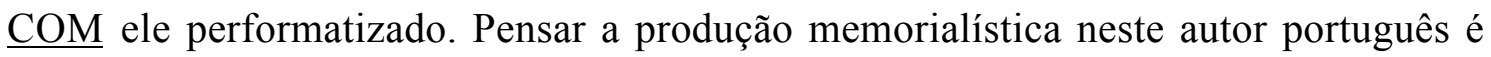
apreender suas estratégias e ferramentas operacionais para acompanhá-lo no que é a sua escrita a fim de compreendê-la. Compreensão não como entendimento obtido na distância e na separação entre leitor e produtor, mas na proximidade, na comunidade com o outro-performatizado.

Portanto, o locus de pesquisa do texto é a escrita não como objeto finalizado. Centraliza-se no escrever como fabulação "[...]no mundo, entre esse sangue estrangulado na minha memória" [HELDER, 2006, p. 09], é produzir-se tal como ele é, singular. Na dedicatória de Photomaton e Vox, aponta-se desde então para uma escrita onde "meu nome, [..] esse nome não o do medo" (HELDER, 2006, p. 08). Se "A escrever é que se aprende o que somos" (HELDER, 2006, p. 66), somos testemunhas, produtos e produtores de nós mesmos a partir de nossas leituras-escrituras: invenções.

Segunda baliza: o corpo é peça principal já que ele é acontecimento comum. Construto inacabado de uma peça e performance "até quando pode a memória, e quanto 
pode, [onde] sou o ator e espectador cúmplice de uma vida dramática, perturbada e irônica." (HELDER, 2006, p. 10). Necessário entender o caráter ficcional da escrita da memória não só porque a experiência é uma invenção, mas porque ela faz parte da criação de um contexto onde Helder pode desenvolver sua poesia, repetindo seus procedimentos a cada vez, performatizando-se.

\section{Estado de Sítio: Medo e Violência}

Sobre a literatura, ou o processo literário já que o centro é um modo de fazer e abordar, pode-se pensá-la como um estado de sitio segundo o próprio autor em Photomaton e Vox.

A relação produzida na literatura se compreende ao serem cartografadas a partir das linhas de fuga que se mantém em constante vibração, e "[...]purificadas das ameaças de confusão, as linhas de força que configuram a equação da consciência e do acto, com suas tensões e fracturas, suas ambivalências e ambiguidades, suas rudes trajetórias de choque e fuga" (HELDER, 2006, p. 54). Na obra Helderliana, vida produzida na literatura ou experiência inventada no texto é feita segundo um contexto de transformações, onde se “[...]propõem formas fiéis aos acontecimentos no seu irredutível vazio" (LOPES, 2003, p. 08).

Para dar rumo a tal fidelidade [cujo significado está além de uma equivalência formal e que será abordado mais à frente], as linhas de força do choque são geradas e dirigidas pela violência; a fuga é produto do medo: estados que produzem um constante movimento de produção de vida: literária. Em Helder, o medo e a violência são operações territorializadoras de um estado sitiado, onde tensionamento e dialética são parte do pacto literário entre experiência - inventada - e texto escrito.

“O medo que faz respirar e viver até a morte" (HELDER, 2006, p. 34), medo da inactividade residual do mundo, quando este "já não consegue propor hipóteses que inquietem, suscitem, movam, comovam" (HELDER, 2006, p. 23) é parte constituinte de uma corporificação. Ao encher

[...]folhas de papel com essa trama subtil e exasperada feita de memória, a atentas expensas de esquecimento. É o relatório do medo lido ao inverso. O balanço pelo forro subtraído de uma irrisória medida pessoal: comida, urina, fezes, esperma, suor. As unhas e os cabelos crescendo sobre um canal de sangue que me corta de cima a 
baixo. [...] Desamor, crueldade, sensibilidade na estranha criatura coroada com sua comida e o seu excremento. Saturada de lágrimas que se escamoteiam pelo favor de uma teoria da força (HELDER, 2006, p. 34).

Um corpo que é construído no inverso do medo tendo o mesmo como motor onde excrementos e sangue percorrem o corpo para coroá-lo após sua autofagia. A constituição corpórea não como objeto final a produzir uma imagem, mas como tagenciamentos, “[...]pontos de causa da escrita [...] que obriga a escrita. $\mathrm{O}$ acontecimento que me faz escrever" (BRANDÃO, 2006, p. 25).

Contudo, este mesmo corpo que é produzido neste momento da escrita e se desfaz instantaneamente para sobre-viver na leitura por outros é violentado constantemente. Uma violência que é própria de um devir-outro em construção.

Construir uma literatura que possa ser lida como autobiográfica a partir de seu efeito sabendo que a todo momento o escritor se faz pela escrita significa pensar a relação memória-esquecimento a partir de "frases que [sic] funcionam como o resto de um movimento dos dedos. Como depois de um banquete: na mesa ficam os restos, e muitos são deixados para o lixo. O que não é resto na escrita é o acto de escrever. [grifo nosso] O banquete é o acto de escrever, não o que fica escrito" (TAVARES, 2004, p. $80)$.

Com Helder, a violência se constrói como estratégia de constituição corpórea de si na medida em que induz a passagens de uma invenção a outra de experiências, a partir de um trabalho laborioso entre uma e outra versão sua de um mesmo texto, prática em que é reconhecido. Implode suas próprias estruturas criadas, fere a própria língua para fazer viver uma nova. Nas suas traduções, ou mudanças para o português como está no título de seus livros de tradução, incorpora a língua primeira, tendo em vista que "[...]trabalha e quase violenta os limites gramaticais da língua para a renovar [actua mais como 'textuante', no plano da sintaxe, do ritmo e das imagens] [...]" (BARRENTO, 2006, p. 178).

Violência que gera um ritmo que dá um desenho próprio do estado de sitio que sua escrita se encontra. Feridas que alteram o texto, redefinido imagens e contextos significantes. Um corpo colocado em marcha processual por ondas de violência, na instantaneidade de sua própria mutabilidade pois se define no ato, o de escrever e nas frases que restam do movimento de seus dedos. 


\section{Corpo}

“A escrita nasce diretamente do corpo, do seu movimento. É um modo de ver a questão.” (HELDER, 2006, p. 128)

corpo-fluido: sangue e paisagem

[...]. Nesta mão que escreve afunda-se a lua, e de alto a baixo, em tuas grutas obscuras, essa lua tece as ramas de um sangue mais salgado e profundo. [...] vivo. A idéia que escrevo escreve-se num braço fincado em ti, uma veia dentro de tua árvore. [...] Queima-te a espaçosa desarrumação das imagens. E trabalha em ti o suspiro de sangue curvo, um alimento violento cheio da luz entrançada na terra. [...] (HELDER, 2006, p. 44)

Com a escrita Helderliana desempenhando a partir da matéria-prima palavra a construção de uma memória, sucessivamente são construídas imagens desta memória inventada - experiências em estado bruto atualizadas no texto produzido - através de uma imagem elementar condutora fluida, o sangue [assim como o ar, a água, o ar, segundo Silvina Lopes, complementado pelo fogo, de acordo com Barrento].

O sangue, fluido conectante de uma estrutura corporal e essencial para transportar, levar, comunicar a fim de manter a vida tem uma função maior, tornando-se palavra escrita que desloca de mim para outro, "num braço fincado em ti, uma veia dentro da tua árvore” (HELDER, 2006, p. 44), estabelecendo planos para uma nova escrita, para novas formas fieis aos acontecimentos em sua atualidade, que abarquem o outro, 
outrando-se como dito anteriormente.

O sangue é imagem ambígua pois no momento em que constrói ligando o esquecimento [fato] ao esquecer-se [ato], "queimando a espaçosa desarrumação das imagens", destrói ordenando um outro mundo, um novo real. Imagem dialética que constrói um corpo para volatilizá-lo logo em seguida. Faz fugir imagens de sua escrita em prol de uma fluidez que adquire substância momentaneamente em sua leituraescritura.

Um corpo é feito ao estender-me a outro através da massa sanguínea, “[...] centro de irradiação e múliplas conexões [...]fluxo fiel primordial [...] interior a um corpo e ao mundo como corpo" (LOPES, 2003, p. 08) de forma a construir uma relação entre a terra e a lua. De elemento a elemento busca-se " [...] assimilar à sua própria obra textos estranhos, por uma via de afinidades electivas, que passam essencialmente pela busca da experiência e da palavra elementares e genésicas" (BARRENTO, 2006, p. 180). Veia dentro da árvore se conforma como passagem que leva o que vem da terra. Pelo fluir, um em-comum com o restante do mundo, aquilo que Helder chama de matéria residual inativa, "[...] o que não é poetizável, o que é rotineiro" (HELDER, 2006, p. 23), se forma no momento, energizando o que antes era inóspito. Formado dentro do braço fincado em ti, na veia de tua árvore, em tuas grutas obscuras, na mão que escreve, um corpo neste instante é feito através de "uma frase cosida ao fôlego, ou um relâmpago / estancado / nos espelhos. E às vezes é uma raiz engolfada, e quando toca / a fundura das paisagens, as constelações mudam / no chão" (HELDER, 2006, p. 09).

Se "tudo se expõe - toda a punjança, todo o luxo - , tudo se joga, numa rede de veias, entre um movimento contínuo de explosão, eclosão, deslocação, passagem, e a maneira como o recorte e encadeamento de versos suspende ou interrompe o aparecer" (LOPES, 2003, p.09.), uma memória deslocada pelo esquecimento proporcionado pelo sangue em constante fluidez dentro do corpo sobre o que se escreve é inventada. A "rede de veias" que circula por todo o corpo, estendendo-o ao mundo, configura-se como uma paisagem por onde um corpo é constantemente redesenhado. É neste sistema de fluxos que são estabelecidos

[...] quer uma série vocabular que diz respeito à circulação de energia e interpenetração de espaços, quer uma outra série que diz respeito aos modos de estabelecer a ligação e a ruptura, quer, ainda, uma particular insistência de processos de simbiose como respiração, alimentação ou 
devoração, e de operações que separam e [ou] reúnem, como cortar, atar, romper ou bater (LOPES, 2003, p.13).

Neste desenho de uma infra-estrutura por onde as imagens são construídas pelo sangue que por ali circula como matéria conectante, o corpo não adquire a imagem poética, mas forma estruturante que dá por sua vez fidelidade à relação entre representação e acontecimento.

Ao circular ininterruptamente produzindo acontecimentos, a escrita é, como o próprio autor define, circular. E daí um paradoxo: se "Tudo acaba onde começa" (HELDER, 2006, p. 164), pois é um texto fechado, sendo circular “[...]nenhuma solução é possível, por nunca se poder provar a hipótese de verdade da coisa escrita", pela impossibilidade de localização do início. Portanto, é “também aberto" (HELDER, 2006, p. 65). Assim, o fluido corporal que liga interior ao interior a ao que está do lado de fora - sendo o mundo um corpo - é corpo movente que produz mais do mesmo de forma diferente onde "Em torno da fria podridão do mundo os papéis escritos são um motor trabalhado inquebrantavelmente. [...] Tudo trabalha a minha volta, íntimo, carregado. A terra pulsa sob um arco extenuamente liso. Enfrento este sonho da terra. O meu poder é obscuro. Desalojo dos labirintos da ciência uma fala essencial, cultivada pela ingenuidade. [...] Talvez eu mesmo comece aqui, neste momento ignorante, onde se faz uma claridade inexplicável [grifo nosso]" (HELDER, 2006, p. 35), pelo qual o autorproduto já passou com o leitor.

\section{corpo comunal}

Nas incorporadas fronteiras, na paisagem infra-estrutural que dá forma a escrita de Helder, "A água que banha as ilhas, e na qual estas se recortam como totalidades fragmentárias, circula entre elas como o seu outro, instaurando-se desse modo uma relação entre morte e vida, parecer e desaparecer [...]” (LOPES, 2003, p. 09.). Uma aproximação com o que está exterior a mim para dele me apropriar, corporificando-se como outro através de fluidos. Não é a ilha, pois "A ilha, sim, essa era uma fábula cuja moralidade ignoro. Só havia água à volta, mais nada" (HELDER, 2006, p. 27).

Assim, água tal como sangue, fluidos que circulam por um sistema de vasos, estabelecem ligações dentro de seu corpus escrito. Apontam ao mesmo tempo para dentro e para o exterior também. Nos contatos interior-interior e exterior-interior o 
corpo biografado, ou cartografado, adquire substância. Por isso, ele só existe como “[...]personagem em acto que a escrita também é” (HELDER, 2006, p. 164).

Tomando o comunal-comum como relação estabelecida pela linguagem que une autor performatizado-leitor, que em Helder diz de um escritor-leitor-tradutor como único (cf. BARRENTO, 2006), pois ler é escrever em seu próprio caderno sua versão, tal como traduzir é copiar para si próprio (BARRENTO, 2006, p. 183), o corpo do escritor português "era a escrita - escrita exercida como caligrafia extrema do mundo, um texto apocalipticamente corporal" (HELDER, 2006, p. 10). Mas jogado para o leitor, que é também autor, pois lê-escreve, e que aqui é Helder, "escrever é literalmente um jogo de espelhos, e no meio desse jogo representa-se a cena multiplicada de uma carnificina metafisicamente irrisória” (HELDER, 2006, p. 12).

Assim, o corpo é campo de forças, ou estado de sitio onde são produzidas num jogo entre vida e morte, ambivalências entre real e virtual, acontecimentos escriturais elementares. Campo de fluidez onde a escrita é canal comunicante entre um e outro, natureza e cultura, donde se "A realidade é um repto. A poesia é um rapto. De uma para a outra queimam-se os dedos, e como é de fogo que aqui se trata, tudo se ilumina" (HELDER, 2006, p. 23). E por isso mesmo “[...] agora amávamos essa queimadura que, com dedos absurdamente inocentes, tocávamos uns aos outros” (HELDER, 2006, p. 29). A queimadura então é ponto de contato que aparece como ferida na carne com o qual tocávamos uns aos outros. Produto de uma violência, o queimar-se é que faz aparecer a carne do corpo em construção durante ato.

Sua poesia não procura alcançar uma verdade para além da aparência, mas joga com a superfície das imagens para estabelecer um jogo de linguagem autoreferencializada [interna] que se dá com a exterioridade do mundo [interior-exterior], em contato com. A mudança constante que Silvina chama de desterritorialização rítmica é que é referência: operação poética hederliana que serve à constituição de um corpo.

\section{corpo silêncio}

Com ritmo, "tudo acaba onde começa" (HELDER, 2006, p. 164): pela capilaridade circular fluida através da escrita atualizada em ato transformador da memória. "As montanhas deslocam-se pela energia das palavras, aparecem pessoas, animais, corolas, sítios negros, e os astros crispados pela energia das palavras, cria-se o 
silêncio pela energia das palavras" (HELDER, 2006, p. 32).

O silêncio impõe-se como barreira e condensador que impede e catalisa a contínua leitura-escritura memorialística. Constitui-se como corpo que contém para depois liberar ao mundo.

Impede o fluxo sanguíneo ao cristalizar momentaneamente a paisagem infraestrutural em imagem corporal performática. Transforma acontecimento, um porvir, em matéria rígida.

Condensa, contém, para depois energizado jogar no mundo por uma rede de canais, acontecimentos, personagens em ato que a escrita é e que se mostram solidificados neste mesmo silêncio. A visão confiante alucinação (v. HELDER, 2006, p. 22) de Helder não é inventada, mas em invenção.

Assim, o silêncio é ponto de partida e de chegada de uma construção escrita em HH. É mudez, "radicalmente [aquela que] personifica o duplo" (HELDER, 2006, p. 164) que aponta para repetir-se, diferenciando-se.

[...] onde, depois, o outro eu, o duplo pessoal, expectamente alternativo, se apronta para a resposta à uma pergunta que é todo o escrito, toda a personagem em acto que a escrita também é. A implícita pergunta escrita envolve uma resposta que o outro desdobrado assume. Essa resposta consiste do mesmo modo numa pergunta. O juntíssimo tecido de interrogações e esclarecimentos, que se reenviam a si mesmos a contínuos modos de questionar e romper as respostas, constitui a própria tensão dinâmica da memória e do texto que a conduz [grifo nosso] (HELDER, 2006, p.24).

\section{REFERÊNCIAS BIBLIOGRÁFICAS:}

BARRENTO, João. Arco da Palavra. São Paulo: Escrituras, 2006.

BARTHES, Roland. Roland Barthes por Roland Barthes. São Paulo: Estação Liberdade, 2003.

BRANDAO, Ruth Silviano. Vida Escrita. Rio de Janeiro: 7Letras, 2006.

HELDER, Herberto. Photomaton e Vox. Lisboa: Assírio \& Alvim, 2006.

Doze nós numa corda. Poemas mudados para o português. Lisboa: Assírio \& Alvim, 1997.

Ouolof. Poemas Mudados para o português. Lisboa: Assírio \& Alvim, 1997.

LEJEUNE, Phillipe. O Pacto Autobiográfico. Belo Horizonte: EdUFMG, 2008. 
LOPES, Silvina Rodrigues. A Inocência do Devir. Lisboa: Vendaval, 2003

NANCY, Jean-Luc. Resistência da Poesia. Lisboa: Vendaval, s/d.

PARAISO, Andrea Correa. Marguerite Duras e os Possíveis da escritura. São Paulo: UNESP, 2002.

TAVARES, Gonçalo. A Perna Esquerda de Paris seguido de Roland Barthes e Robert Musil. Lisboa: Relógio d'Água, 2004. 